\title{
Response Article: Voices That Shall Be Heard
}

\section{Dragan Milovanovic}

There once seemed such a simple plan. All that needed to be done with those who lived a marginal existence, or with those whose behavior was deemed too far from the center, or with those who were caught in the net of social control was to reproduce an ideal machine which would discipline them in the correct ways of the dominant groups. Specialists would guide those poor souls back to salvation and society would re-absorb the wayward. Do-gooders materialized overnight. Politicians preached the good word of salvation. Guards, social workers, psychiatrists, and administrators guided these poor misdirected to the ideals of society. As a mechanistic entity, the prison-machine appeared in the early nineteenth century in the United States. Duplicated world-wide, this model of the prison became the ideal machinery for constructing, as Foucault tells us in Discipline and Punish, docile bodies, bodies of utility necessary to the smooth functioning of the newly-emergent order. Since the ninteenth century, this machine has taken on its own life, its own momentum, and anything that resists its logic suffers the fate of its irresistible weight.

This is the new age, the age of the prison-machine. Its logic exemplifies orderliness, control and coordination. Ultimately, it is the force that would change the wayward. In the U.S. alone the prison population has tripled over the last fifteen years, now hovering at the 700,000 mark; prisons cost $\$ 15$ billion a year to operate, with yet another $\$ 3$ billion earmarked to construct even more. It is within this context that we must listen to those who would be the target of this Leviathan.

In the essays appearing in this volume we find voices that would normally be denied an ear, except from those within the closed setting of the prison who might care to listen. It has become very clear to me in my experiences teaching prisoners in jails, counselling youth in detention centres, inspecting prisons with the John Howard Society, and in doing theoretical research that as these voices increasingly find an audience outside of the prison, that audience may not be hearing what they would wish to hear; however, due to the sheer magnitude of the prison-machine, they are hearing what they

The author would like to thank Dr. Brian MacLean and two anonymous reviewers for their helpful suggestions on earlier drafts of this manuscript. 
must begin to face.

The essays can be organized in terms of two foci: the essays by Little Rock Reed, Arthur Solomon and Danny Homer deal with the question of imprisoned Native peoples; the letters from C.J. Hinke and Susan Rosenberg deal more centrally with the question of political prisoners. (Although, it is quite clear, that the first three essays are implicitly about political prisoners as well.)

The first three essays highlight the conditions of imprisoned Native peoples. Each represents a unique style of presentation; each points to attempts by the dominant group, through their operatives (C.W.Mill's "cheerful robots"), to extend its hegemony and bring within its orbit those who have been wayward. Denied in this process are indigenous forces seeking to work within their own cultural heritage in attempts to bring about change. Each essay represents a human voice that is reaching out and saying with great emotion:

Here we are, here is our cultural heritage that you the 'white man' have destroyed and who now seek to deny those of us who stir to revive what has been left in the ashes. But we will be heard; your machinery of rehabilitation so well coordinated with credentialed lackeys, so replete with self-justifactory rationales for its existence, so well oiled by the thoughts of the age will not keep our voice unheard. Peace will not come from above but will materialize only with toleration, recognition, and mutual acceptance of cultural diversity. You cannot rehabilitate those of us who have faced your deceitful lies. But we do not deny the problems that face our Native peoples, and we do have our own ways of working with those who have suffered for so long. Let us be heard about our ways.

Little Rock Reed's article epitomizes the plight of Native peoples. He argues how Alcoholics Anonymous (AA) programs are being forced upon Native peoples, albeit by the promise of reduced time served with participation. The rationale of prison officials is rather simple: since many Native peoples have committed crime (or have been accused of committing crimes) while under the influence of alcohol, then, programs such as AA are inherently beneficial. Therefore, participation in AA should be a mandatory 'special condition' attached to parole eligibility or early release. As a result, resistance to these programs is often used as an example of incorrigibility or uncooperative behavior (See, also, Milovanovic and Thomas, 1989; MacLean and Ratner, 1987). The point is not whether AA works in fact, much evidence indicates that it works quite well for those who truly want to stop drinking - the real question has to do with cultural sensitivity and Little Rock Reed argues that it is only with this sensitivity that such rehabilitation programs have any chance of real success. He goes so far as to say, and I certainly would agree, that many of the so called prison rehabilitation programs are merely tools for the production of docile bodies and bodies of utility (e.g., on the one 
hand keeping the prisoners busy, on the other inculcating them with values in accord with the capitalist political economy). What effectively has taken place is a displacement of concern away from poverty, unemployment and repressive hierarchical machineries, towards the need to control, transform and reproduce an ideal conception of the good subject. The real problem is the inability (or refusal) of the dominant culture to accept the inherent problems it faces and which it cloaks in ideologically distorted ways, always substituting mechanisms that would reconfirm the dominant cultural ethos. It is not, methinks, Little Rock Reed's argument that problems do not exist. Rather, he implies that indigenous solutions already exist but are being denied their material expression. For example, the United Native Alcohol Program revives Indian spiritualism and culture in addition to incorporating other techniques found to be generally successful in its program. But why has it been received rather badly by prison authorities? Reed argues convincingly that another agenda exists - one that would deny cultural diversity, one that would subsume all within the dominant order.

Arthur Solomon, a Nishnawbe Spiritual Teacher, authors a poem on the plight of Native peoples. It commands that we be sensitive to the alternate channels, genres, and styles of communication employed by the imprisoned. At one time, when teaching classes at a maximum security jail for men, I often would be confronted with student/prisoners expressing their insights in emotional terms. As a scientist, I would emphasize that a 'good' argument is one in which the writer does not get 'emotional'. Rather, s/he logically develops a particular point and expresses it in a non-emotive, detached and rational way. Soon I realized my preposterous naiveté. By quietly enforcing a cold, cutting, white, masculine rationality, I was unwittingly denying the genre of expression of those who had already been denied their voice by a legal process. By translating my students' experiences into a legalistic conception of the world, the legal system had redefined their cultural reality. I then came to realize that speaking with passion, emotion, and the whole self is a more human form of self expression. In my subtle attempts to condition the prisoners to use the "appropriate" style of argumentation I, myself, was being subtly transformed into an appendage of the prison machine. Temporarily and subtly I had been co-opted. Enforcing a dominant form of expression, even if unwittingly, is an oppressive act. All too often, cultural workers (including teachers) within the prison machine reconstruct an uncritical appreciation of what is a "good argument" by forcing the kept to communicate in a form which is removed from the feelings that propel their inner voices to speak out. Arthur Solomon lists the many attempts by the disenfranchised to enforce these alien mechanisms under the misconception that they are necessary for 
Native peoples to function in the world dominated by white, bourgeois, masculine rationality. He speaks from his native heart with a language that defies dominant ideology - a form of expression that is alive with meaning. All too often academicians and administrators practice a form of cultural imperialism - a practice which seeks to modify, control and dominate, not one which seeks to understand. Arthur Solomon resists this practice and attempts to re-capture a way of communication, a way of being, a way of revolt.

Danny Homer continues the plea to revive Native voices. He argues that Native spirituality in prisons has begun to emerge. It is the spiritual dimension, he tells us, that will provide the way. In his words: "As a person grows spiritually, one's perspective of the world takes on a different meaning. The individual comes to understand what is happening around her/him and is able to adapt to and change the environment." Spirituality, he tells us "...keeps the individual in touch with the Native community and in touch with the Native tradition. It serves as a means of survival in the foreign environment of prisons; the prison experience is altered as a result of the commitment." It has been the white person who has attempted to deny this spirituality through hegemonic mechanisms such as the prison-machine.

The first three essays are rich with feeling, emotion, a longing to recapture denied spirituality and a search for peace. In current critical criminological thinking, Richard Quinney (1989) comes closest to being harmonious with the first three authors in his "Criminology as Peacemaking". In Quinney's work, I believe we can identify an intersection of a leading, radical intellectual force and those who witness first hand the violence of our criminal justice system:

We are fully aware by now that the criminal justice system in this country is founded on violence. It is a system which assumes that violence can be overcome by violence, evil by evil...The radical nature of peacemaking is clear: no less is involved than the transformation of our human being. We continue to be engaged in action, but action comes out of our transformed being. Rather than attempting to create a good society first, and then trying to make ourselves better human beings, we have to work on the two simultaneously. The inner and the outer are the same. The transformation of ourselves and the world becomes our constant practice, here and now. The practice is in the true sense spiritual and religious as well as material (Quinney, 1989: 5).

The last two essays are more outwardly 'political' in their thrust. C.J. Hinke gives a personal recollection of his attempt to counter large exploitative corporations pilfering the land. He personifies an individual in struggle, living his convictions in his attempt to halt the raping of our land. How many of us would dare to do as he did (and continues to do) ? Would we dare to interpose our own bodies as a way of combating the powers of the heartless, profiteering, massive corporations - entities with no soul, no feelings, and no sense of 
humanness - guided only by the lure of the almighty dollar? Yes, C.J. Hinke sees himself as a political prisoner in his rebellion against the exploiters of native land claims. His personal recollections of his fight against loggers and his resolve to save the stolen lands, within the formal mechanisms of law itself, is telling for all political prisoners. In their actions and in their abandonment, these actors provide "free" citizens more freedom. Ironically, in so doing, they also produce the desire by hegemonic groups to develop increasingly ubiquitous forces which are more pervasive and more omnipotent than ever. The irony of much rebellion and the small gains of freedom is often that at the end of the road of liberation is a machinery which is more repressive, yet more hidden than that which was in existence before. And implicit in C.J. Hinke's argument is that law itself is the mechanism that cloaks reality, denying in the process a forum for genuine discussion of the burning issues of the age.

Susan Rosenberg carries this argument further. Convicted of weapons possession Rosenberg was sentenced to the unprecedented fifty-eight years imprisonment (typically those sentenced for killing another human being spend less than ten years in prison). She articulately presents the case for 150 political prisoners in the U.S. at a time when the dominant group argues that not one exists in the land of freedom (See also Can't Jail the Spirit: Political Prisoners in the U.S.). The courts very effectively maintain the rule of law ideology by simultaneously constructing the appearance that defendants will have their day in court while subtly repressing perspectives that are counter to the interests of hegemony (Also see Milovanovic, 1988; Milovanovic and Thomas, 1989; Bannister and Milovanovic, 1990). Nationalist groups such as Puerto Rican Independista freedom fighters have been dealt with harshly in U.S. prisons by practices such as long term solitary confinement, harassment, and brainwashing techniques. With few exceptions, the courts endorse the façade that no political prisoners exist - a façade which operates in the interests of hegemony.

In conclusion, these five essays express various dimensions of the violence inflicted in the name of the people upon Native peoples and rebels struggling for the independence of their homeland and/or their cultural integrity. But the powers that be do not rest idly as they spin out yet more creative mechanisms of control, "rehabilitation", and rationales for the dominant order. Cheerful robots to run the repressive apparatus are found everywhere. The prison-machine has been discovered and rewards those who fall into step while ruthlessly crushing dissenters. Given the current magnitude of the rising rate of imprisonment and the projections it yields into the 1990s, a number of questions emerge: will there come a time when new more lethal 
methods of control, surveillance, and "rehabilitation" will be discovered? Will these be accepted in the crisis atmosphere being generated ? Will these render the prison itself obsolete? Could it be that the techniques and mechanisms that are being tested in the prison will become increasingly applied to the free citizen? We already begun to chart this course with already much talk and use of electronic surveillance techniques (See, for example, Marx, 1988). Perhaps the voices that are being repressed from the prisons will begin to be heard. Perhaps these may eventually provide keen insight into the prisonworld currently in the process of gestation.

\section{REFERENCES}

Bannister, Shelley and Dragan Milovanovic (1990), "The Necessity Defense, Substantive Justice and Oppositional Praxis," International Journal of the Sociology of Law, vol 18.

Bannister, Shelley and Dragan Milovanovic (1990), Can't Jail the Spirit: Political Prisoners in the U.S., Chicago, Illinois: Editorial El Coqui Publishers. (Can be ordered by sending $\$ 12.00$ and postage to $1671 \mathrm{~N}$. Claremont, Chicago, Illinois, 60647).

Foucault, Michel (1977), Discipline and Punish: The Birth of the Prison. New York: Pantheon Books.

MacLean, B.D. and R.S. Ratner (1987), "An Historical Analysis of Bills C-67 and C68: Implications for the Native Offender." Native Studies Review, 3 (1):31-58

Marx, Gary (1988), Undercover: Police Surveillance in America. Berkeley, California: University of California Press.

Milovanovic, Dragan (1988), "Jailhouse Lawyers and Jailhouse Lawyering." International Journal of the Sociology of Law 16: 455-475.

Milovanovic, Dragan and Jim Thomas (1989), "Overcoming the Absurd: Legal Struggle as Primitive Rebellion." Social Problems 36(1): 48-60.

Quinney, Richard (1989), "The Theory and Practice of Peacemaking in the Development of Radical Criminology." The Critical Criminologist 1(1): 5. 